\title{
Resignificaciones identitarias en el archipiélago de Chiloé. Discursos e imaginarios sobre el Mayo Chilote
}

Resignifications of Identity in the Chiloé Archipelago.

Speeches and Imaginaries about Mayo Chilote

Resignificações identitárias no arqhipélago de Chiloé.

Discursos e imaginários sobre o Mayo Chilote

Pablo Andrés Robledo Vallejos*

Gonzalo Peña Barriga**

Recibido: 12 de octubre de 2018

Aprobado: 16 de agosto de 2019

Doi: https://www.doi.org/10.12804/revistas.urosario.edu.co/territorios/a.7313

Para citar este artículo:

Robledo Vallejos, P. A., \& Peña Barriga, G. (2020). Resignificaciones identitarias en el archipiélago de Chiloé. Discursos e imaginarios sobre el Mayo Chilote. Territorios (43), 1-26. Doi: https://www.doi. org/10.12804/revistas.urosario.edu.co/territorios/a.7313

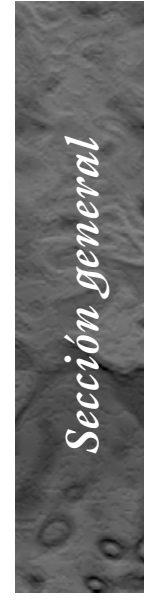

\footnotetext{
* Universidad Alberto Hurtado. Investigador en Grupo de InvestigaciónAcción Kutral. Correo electrónico: probledovallejos@gmail.com.ORCID: https://orcid.org/00000001-7297-3205

** Universidad Alberto Hurtado. Investigador en Grupo de InvestigaciónAcción Kutral. Correo electrónico: gonzalopenab@gmail.com. ORCID: https://orcid.org/00000002-3794-9768
} 
Palabras clave

Chiloé, identidades, industria salmonera, territorio.

Keywords

Chiloé, identities, salmon industry, territory.

Palavras-chave

Chiloé, identidades, indústria de salmão, território.

territarios 43
RESUMEN

El presente artículo interroga los discursos de identidades de resistencia al proceso de industrialización en el archipiélago de Chiloé, concentrándose en las valoraciones de las movilizaciones sociales del Mayo Chilote. A través de una metodología de investigación cualitativa y exploratoria, se realizó un análisis de contenido en el cual se identificaron las particularidades discursivas para generar un estudio que caracterizara los discursos de forma profunda y comprensiva. Se analizan las valoraciones del movimiento social considerándolo como la imagen de una gramática discursiva desde sujetos activos de dicho movimiento y el potencial de proyección de aquellas identidades de resistencia como eventual proyecto de sociedad local. Se concluye que existen claras tensiones en las distintas identidades locales, focalizando los resultados en las particularidades de las identidades de resistencia que limitan sus posibilidades de proyección debido a un autorreconocimiento aún no consolidado.

\section{ABSTRACT}

The present article interrogates the discourses of identities in resistance to the industrialization process in the Chiloé archipelago, focusing on the valuations of the social mobilizations of Mayo Chilote. Through a qualitative and exploratory research methodology, a content analysis was performed, in which the discursive particularities were identified to generate an analysis that characterized the discourses in a deep and comprehensive manner. The valuations of the social movement are analyzed considering it as the image of a discursive grammar from active subjects of said movement and the projection potential of those resistance identities as a possible local society project. The article concludes that, there are clear tensions in local identities, focusing the results on the particularities of the identities of resistance that limit their possibilities of projection due to a self-recognition that has not yet been consolidated.

\section{RESUMO}

O presente artigo questiona os discursos de identidades de resistência ao processo de industrialização com o arquipélago de Chiloé, concentrando-se nas valorações das mobilizações sociais do Mayo Chilote. Através de uma metodologia de pesquisa qualitativa e exploratória, se realizou uma análise de conteúdo na qual se identificaram as particularidades discursivas para gerar uma análise que caracterizara os discursos de forma profunda e compreensiva. Se analisam as valorações do movimento social considerando-o como a imagem de uma gramática discursiva desde sujeitos ativos de dito movimento e o potencial de projeção daquelas identidades de resistência como eventual projeto de sociedade local. Conclui-se que existem claras tensões nas distintas identidades locais, focalizando os resultados nas particularidades das identidades de resistência que limitam suas possibilidades de projeção devido a um auto reconhecimento ainda não consolidado. 


\section{Introducción}

El imaginario cultural del archipiélago de Chiloé actualmente aparece permeado por una tupida tensión entre las tradiciones culturales históricas y las dinámicas que intentan asentar las lógicas de la modernidad y sus códigos, teniendo por nodo primigenio la implantación de la industria salmonera ${ }^{1}$ durante la década de 1980. A la base de esta tensión se alberga una implicancia que acarrea profundas transformaciones, pero también un proceso de amenaza frente a lo que hasta ahora ha sido (Berman, 1978). Si bien es cierto que el Estado-nación asienta ciertas dinámicas modernas en el escenario chilote, es con la llegada de la industria salmonera donde el espacio vivido se ve más profundamente afectado, siendo amparada por las disposiciones gubernamentales del Estado-nación y su marco legislativo. Así mismo, los habitantes de Chiloé se han visto afectados por crisis sanitarias producidas a partir de las operaciones de la industria salmonera, así como también por las condiciones laborales nuevas en el contexto del archipiélago, que además implicaron crisis y reconfiguración en el mundo del trabajo.

En el presente artículo, se busca analizar discursos de chilotes y chilotas en relación con el proceso de movilización colectiva desarrollado durante el año 2016, conocido como 'Mayo Chilote', considerándolo como la expresión de una gramática identitaria particular. Estas movilizaciones se dan en un contexto en el que pescadores artesanales exigen al gobierno de Chile una compensación monetaria debido al fenómeno de marea roja, ${ }^{2}$ consistente en la aparición de microalgas que pueden ser nocivas para la salud humana. Ello no les permite a los pescadores entrar al mar y trabajar, lo que se suma a la existencia de un escenario permeado por nuevas legislaciones que dificultan el trabajo independiente. Todo esto ocurrió dentro de un contexto de incertidumbre respecto de la responsabilidad de la misma industria salmonera, debido a que el vertimiento de una gran cantidad de mortalidad de salmones estuvo presuntamente asociado a este fenómeno (Radio Universidad de Chile, 2018).

En dicho escenario, diversos actores sociales - entre los de más renombre, sindicatos de pescadores artesanales - fueron parte del proceso de movilización que mantuvo cortadas las rutas del archipiélago por casi tres semanas: a este período se le conoce como el Mayo Chilote. En específico, las movilizaciones se iniciaron el primer día del mes de mayo, generándose mesas de negociación compuestas por dirigentes sindicales que tuvieron que dialogar con autoridades de gobierno tales como Raúl Súnico, subsecretario de Pesca de la época. Ya a día 18 de mayo de 2016, 14 de 15 comunas del archipiélago habían depuesto la movilización, quedando solo Ancud en pie durante un día más. A pesar de lo fugaz del proceso, distintos y enriquecedores procesos de resignificación identitaria
- Se considera la llegada de la industria salmonera como el inicio de un periodo de industrialización que, entre otros elementos, implicó una movilización de población, paso de trabajadores independientes bacia un modo asalariado (Gobantes \& Frias, 2015), así como la incorporación de distintas tecnologias y servicios.

2 Existe documentación que señala elementos de responsabilidad de la existencia de dicho fenómeno en el desarrollo de la salmonicultura en la zona, como se señala en los trabajos de Álvareze Hidalgo (2018) o Valdebenito (2018). A su vez, hay versiones que sugieren que no hay una responsabilidad directa comprobable de la salmonicultura en tal proceso, como sugieren Buschmann, Farias, Tapia, Varela y Vásquez (2016) o Seguel (2008). En este contexto, se inserta una constante tensión entre ciertos discursos expertos, en contraste a los de los actores que viven en el territorio y que están detallados en la discusión de resultados expuestos en el articulo.

territarias 43 
fueron gatillados en el archipiélago de Chiloé, con repercusiones profundas en la construcción de los diferentes imaginarios asociados a la resistencia territorial local.

\section{Acerca del lugar: industrialización y nuevo régimen laboral}

La industria salmonera en el archipiélago de Chiloé tiene una historia relativamente reciente, apenas en la década de 1970 comienzan a instalarse las primeras piscinas de cultivo, sin embargo, rápidamente esta actividad económica comenzó a incidir sobre distintas aristas de la configuración social, cultural y económica de Chiloé. Por un lado, la salmonicultura significó la llegada de un régimen de trabajo asalariado que hasta la fecha existía de manera escasa en el archipiélago, puesto que hasta entrado el siglo Xx la economía de subsistencia se basaba en una extracción relativa de flora y fauna de bajo impacto, que además estaba mediada por las estaciones del año; ello provocaba migraciones estacionales en el interior del archipiélago: era común en estas latitudes que las familias se movieran de la costa al monte con todas sus pertenencias, casas incluidas, lo cual señalaba lo multifacético de las formas de extracción.

La instalación, desarrollo y consolidación de la industria salmonera supuso una serie de complejidades. En primer lugar, hubo un cambio en la matriz económica dominante que generó un impacto ecosistémico que al día de hoy es posible observar y resentir sobremanera. La industria salmonera, al ofrecer puestos de trabajo formales, con una temporalidad rutinaria estable y con un sueldo fijo, significó el tránsito de una economía autónoma a una proletarización de la población, así como también el acceso de estos a nuevas tecnologías, bienes y servicios. Lo anterior igualmente repercutió en procesos de inmigración hacia el archipiélago, debido a las nuevas oportunidades de empleo, pero también un fuerte proceso de migración interna, particularmente desde las zonas rurales hacia los centros urbanos, que es donde se ha concentrado la empleabilidad de la isla.

En este contexto, los primeros años del siglo XXI vieron cómo la promesa del desarrollo del archipiélago de Chiloé, traída por la industria salmonera, trastabilló al verse afectada por las primeras crisis socioambientales, particularmente durante el año 2009 con la crisis del virus ISA y el año 2016 con la emergencia de la marea roja producto de grandes toneladas de mortalidad de salmones arrojadas en las proximidades de la costa de Ancud, ciudad ubicada al norte de la Isla Grande de Chiloé. Este último hecho significó la aplicación de un período indefinido de veda para los pescadores de la isla, situación que se refuerza debido a las limitaciones y perjuicios originados en el marco de la Ley de Pesca promulgada años antes.

El proceso de consolidación de la industria salmonera implicó una configuración de un sinnúmero de elementos 
fundamentales en Chiloé, entre ellos se destaca la predominancia de las concesiones marítimas a las empresas pesqueras, la proletarización de los chilotes, y, además, significó la inserción de la economía del archipiélago y sus habitantes en los flujos del capital trasnacional, que trajo como consecuencia una reorganización del régimen de propiedad impulsada por la industrialización (Román, 2015; El Mostrador, 2016; CECA, 2017).

Este proceso de industrialización y cambio de propiedad también vino aparejado con un nuevo régimen laboral que conllevó un paso de relaciones de intercambio y trueque a la predominancia del dinero como medio legitimado (Román, 2015). Así mismo, en este escenario cambiaron las formas de relación económica entre ser humano y naturaleza, un ejemplo de ello son los pescadores artesanales que prestan sus servicios de mano de obra e infraestructura de pesca a las grandes industrias (Bustos, 2015). En tal sentido, la tensión se manifestó en las prácticas y resignificaciones culturales asociadas a la territorialidad misma. Por lo tanto, el proceso de consolidación de la industria salmonera y la consiguiente movilización de recursos en el archipiélago de Chiloé terminó por derramar sus influencias en las prácticas tradicionales que históricamente han estado arraigadas al territorio chilote:

La industria salmonera ha afectado mucho esto, más aún con respecto a la vida familiar y nuestro entorno, ha afectado nuestra isla, con toda la destrucción que han hecho y han dejado en nuestro planeta. Ellos decían que venían con las salmoneras a dar un trabajo a la gente, a vivir y dar lo mejor en prosperidad, pero no ha sido tan así porque la prosperidad no significa las cosas materiales que uno adquiera durante el trabajo que tenga, para mí esa no es la prosperidad (persona participante del movimiento huilliche, comunicación 3 de septiembre de 2016).

En este escenario, signado por los cambios en el tejido social, cultural y económico producto de la explotación salmonera en la región, el presente artículo tiene como objetivo analizar los discursos que dan cuenta de la trama identitaria vinculada a la categoría de territorio, desde participantes del Mayo Chilote, en el contexto del desarrollo de la industria salmonera de la Isla Grande de Chiloé. De forma específica se busca: 1) analizar la relación que se teje entre la identidad chilota y el territorio chilote; 2 ) identificar la percepción de participantes del Mayo Chilote sobre el archipiélago de Chiloé desde la categoría de territorio, asociada a sus experiencias personales; 3 ) establecer una relación entre la identidad chilota y las movilizaciones de mayo de 2016, desde las voces de diversos participantes de estas.

\section{Metodología}

La presente investigación es de carácter cualitativo y exploratorio. Fueron 
realizadas diez entrevistas semiestructuradas a ocho personas residentes en la ciudad de Ancud y a dos personas chilotas y vinculadas a las movilizaciones del Mayo Chilote ajenas a esa ciudad, dado que se trató de informantes que tenían un amplio conocimiento y experiencia de participación en otras instancias movimentales locales, cuyas entrevistas fueron consideradas como medida de comparación discursiva con respecto del resto de la muestra. El análisis se realizó de forma focalizada en Ancud, puesto que permitió establecer una similitud geográfica entre las y los entrevistados, pero cabe mencionar que son personas que durante las movilizaciones se vieron expuestas a situaciones similares durante dicha contingencia, haciéndose parte de procesos de corte de rutas locales y de generación de espacios de crítica y reflexión social. Además, se efectuó una triangulación metodológica, llevando a cabo documentación de prensa y de estudios vinculados a la temática abordada.

Por lo tanto, se buscó generar criterios que otorgaron a las y los entrevistados una cierta especificidad a la muestra con respecto a la población (Hernández Sampieri, 2014). Esta particularidad trató de ahondar en un grupo humano que proporcionó un contenido nuevo a los estudios hechos sobre y desde el archipiélago de Chiloé en esta materia. De esta forma, se logró obtener datos de perspectivas y discursos que fueron de interés para la misma población la producción de conocimiento científico. En este sentido, realizar las entrevistas en la ciudad de Ancud permitió expresar las características particulares dentro de un sector del archipiélago, pues, siendo una de las ciudades más importantes del archipiélago, también refleja un nivel de industrialización menor con respecto a otros puntos de la zona, generando un contrapunto interesante de abordar, ya que presenta una relativa lejanía con la industria salmonera y, al mismo tiempo, se ve fuertemente afectada por bajas oportunidades de empleo.

La construcción de la muestra se hizo en conjunto con un informante clave vinculado al entorno y al grupo de interés. La muestra se constituye de personas que fueron reconocidas entre sus comunidades como miembros activos del Mayo Chilote, sin ser necesariamente dirigentes formales. Por lo tanto, dado que se busca indagar en discursos asociados a expresiones identitarias, la metodología de análisis fue cualitativa, para posteriormente efectuar análisis de contenido desde un prisma genéricamente fenomenológico, que trató de originar una comprensión integral del escenario analítico (Mella, 2003). En un ejercicio de libertad investigativa, se optó por tomar elementos de aquel enfoque sin adherir totalmente a él (Sandín, 2003).

Con ello, se buscó lograr un entendimiento profundo de un tipo particular de sujeto social, que sería aquel que presenta una postura crítica y activa respecto del proceso de industrialización en el 
archipiélago de Chiloé. Este ejercicio requirió de descripción y análisis de dichos discursos (Hernández Sampieri, 2014). Así, fue posible realizar un ejercicio heurístico del contexto y momento en que se encuentra el archipiélago de Chiloé, desde perspectivas que emergen disidentes respecto al discurso instituido por las distintas instituciones afines al proyecto de industrialización.

En términos analíticos, se llevó a cabo un análisis de contenido que extrajo información a partir de las dimensiones: discursos identitarios, formas de vida, Chiloé como territorio y valoraciones del Mayo Chilote. Desde allí se identificaron particularidades discursivas que permitieron generar análisis de la realidad territorial y así lograr caracterizar los discursos de forma profunda y comprensiva (Bogdan \& Taylor, 2009).

\section{Territorio, identidades e imaginarios sociales: aproximación conceptual a una gramática identitaria}

De acuerdo con lo anterior, es necesario enunciar las implicancias de un intento de modernización geográficamente situado en el contexto del archipiélago de Chiloé. Milton Santos (2007) considera al territorio como un espacio en que convergen un sinnúmero de fuerzas y condicionantes estructurales, así como actores diversos. No obstante, lo característico de este concepto es la apropiación del espacio para otorgarle un uso y potestad, el cual deviene en elementos que expresan una carga identitaria y de pertenencia a dicho territorio (Berroeta, Ramoneda, Rodriguez, Di Masso \& Vidal, 2015).

\section{Lógicas modernistas: tensión entre pasado y futuro}

Santos (1996a) da cuenta de una disonancia entre el espacio vivido y el espacio global: en el caso particular de Chiloé, este conflicto aparece por discursos sobre distintas formas de valoración respecto del territorio chilote $y$, por consiguiente, diferentes pretensiones de uso vinculadas a las lógicas modernistas, donde las instituciones privadas o estatales detentan el control sobre el territorio más allá de las disposiciones de los lugareños.

Esta tensión se vuelve fundamental en la comprensión del archipiélago de Chiloé hoy día, pues implica una disonancia valorativa y práctica entre dos formas distintas de concebir un mismo espacio. Teniendo en cuenta un contexto de modernización, para Santos (1996b), la naturaleza se ve convertida íntegramente en algo productivo. En este sentido, la modernidad supone una delimitación y separación con el pasado tradicional (Beriain, 1996). Giddens (1995) plantea que las lógicas modernistas conllevan una relación de incertidumbre con el futuro, lo cual redunda no solo en un quiebre con el pasado tradicional, sino también con la certeza de los futuros posibles. 
En este contexto, se puede comprender al territorio como una construcción social (Benach \& Albet, 2010), donde convergen pugnas entre poderes (Foucault, 2003) y distintas expresiones de racionalidades (De Sousa Santos, 2013). En otras palabras, el concepto territorio tiene una profunda implicancia vinculada a las formas de socialización y de subjetivación (Berroeta, Ramoneda, Rodriguez, Di Masso \& Vidal, 2015), generando apego e identificación, que repercute en las tramas identitarias cotidianas de sus habitantes (Santos, 1996a).

\section{Gramáticas sobre la realidad: identidades, territorios y sentidos de pertenencia}

Para Castells (1999), la identidad es una construcción de sentido con una raigambre cultural, a la cual se le otorga una importancia fundamental por sobre otros aspectos: la identificación otorga sentido $\mathrm{y}$, por lo tanto, la identidad local implica un reconocimiento colectivo. A partir de ahí, el pasado puede aparecer en el presente como nodo articulador de aquellas identidades locales, produciendo una inercia que habilitaría el reconocimiento entre estas, a fin de vislumbrar un proyecto futuro (Orduna, 2012). Por lo tanto, las identidades pueden conceptualizarse como "un conjunto de rasgos o cualidades móviles con las cuales las personas o grupos se sienten vinculados" (Molina, 2011, p. 61).

Sin embargo, las construcciones identitarias no están exentas de tensión. En el presente caso aparecen, por un lado, identidades tradicionales enraizadas en sus biografías, pasados y memorias; y, por otro, la estandarización que se exige hacia los actores sociales (Molina, 2011). A partir de esa premisa se rescatan tres tipos de identidades: 1) la identidad legitimadora - referente a la introducida por instituciones dominantes de la sociedad para extenderla y racionalizarla frente al resto del espectro social-; 2) la identidad de resistencia - generada por los actores estigmatizados por la lógica de la dominación, con base en principios disidentes respecto a los valores legitimados por las instituciones dominantes-; y 3 ) la identidad proyecto - cuando los actores sociales, basándose en los materiales culturales de qué disponen, construyen una nueva identidad que redefine su posición en la sociedad y, por ende, transforman esta última- (Castells, 1999).

Precisamente, es a través de la relación entre identidad, sentido de pertenencia y territorio que debe contextualizarse la emergencia de determinadas expresiones colectivas, en tanto ellas pueden entregar rasgos culturales con demandas de naturaleza política (De Sousa Santos, 2001). “De ahí que lo cotidiano - que es por excelencia el mundo de la intersubjetividad- sea la dimensión espacio-temporal de la vivencia de los excesos de regulación y de las opresiones concretas en que ellos se desdoblan" (De Sousa Santos, 2001, p. 179). Desde esta perspectiva, pueden 
expresarse distintas formas de imaginarios y códigos particulares (Cegarra, 2011).

El concepto de imaginario social implica, en primera instancia, una mención a la sociedad como institución. A partir de allí, Castoriadis realiza una justificación ontológica de dicho concepto aludiendo al carácter de producto y parte del proceso histórico y social (Pérez, 2017) y también de autocreación (Castoriadis, 1997): la sociedad está compuesta de un aspecto funcional y otro imaginario (Castoriadis, 2013).

De esta forma, el imaginario social implica una referencia al escenario histórico en el cual se hayan los sujetos sociales (Ugas, 2007), lo cual conlleva una 'gramática’ referencial de comprensión respecto de la realidad social y colectiva (Cegarra, 2012). Así, el imaginario social en Castoriadis se sintetiza como imaginarios instituidos; es decir, como significaciones legitimadoras (Agudelo, 2011), a la vez que los imaginarios instituyentes tienen un componente que potencialmente puede ser creador (Cancino, 2011). En consecuencia, hacen referencia tanto a una cristalización como al potencial de movimiento (Pérez, 2017).

\section{Tensiones identitarias en Chiloé: resignificación cultural del territorio}

La transformación del tejido social y cultural de Chiloé se inserta dentro de una dinámica de flujos de capital generados por la industria salmonera, deslocalizándose y volviéndose escasamente susceptible a ser regulada por las autoridades locales (Román, 2015). No obstante, esta falta de regulación gubernamental no es un impedimento para que este tipo de industrialización sin arraigo ni identificación con el territorio cree nuevos accesos a comunicaciones, modos de vida y tecnologías en el archipiélago de Chiloé. Aquello deviene en formas específicas de sujetos que, en palabras de Marcuse (1971), darían cuenta de un estado distinto y más completo de alienación donde las personas se reconocen en las mercancías que consumen y adquieren, generando formas de control sustentadas en dichas necesidades.

Este proceso donde el sistema económico y político impone formas de ser y de relacionarse con los otros puede ser interpretado como formas de violencia estructural (Bourgois, 2009), en las que fuerzas que están por sobre los individuos ejercen una influencia en ellos a fin de incidir sobre sus comportamientos (Foucault, 2003). Estas mismas disposiciones de una sociedad de mercado transnacional incorporaron nuevos repertorios en la trama territorial, que parecen tener relación con una transformación, precarización y dependencia laboral que escapa al control local de sus habitantes. En este contexto, es que se considera como punto de inflexión el inicio y desarrollo de la industria salmonera en el archipiélago de Chiloé, asistiendo a una reconfiguración que se identificaría dentro de los procesos de transformación social. territarias 43 
Respecto de las incidencias y cambios culturales asociados al territorio, se debe considerar que la cultura chilota "es una mezcla de las costumbres de los habitantes nativos de la isla conocidos como huilliches y de los colonizadores españoles" (Claude \& Oporto, 2000, p. 43). Por su parte, la cultura chilota tradicional se ve relacionada con las características geográficas del territorio (Mansilla Torres, 2006), la cual incide en la predominancia de lazos y comunicaciones tradicionales-campesinas. Ello se explicaría en la lejanía geográfica que posee el archipiélago respecto del centro nacional, no debiéndose ignorar tampoco la relación identitaria que guarda el imaginario sobre el territorio como categoría vinculante entre la naturaleza y el ser humano (Román, 2015).

En este contexto, la emergencia de nuevas formas de administrar el territorio producto de la irrupción de la industria salmonera tensionaron las identidades, afectando modos de vida y la manera como en el archipiélago de Chiloé se reconfiguró el espacio habitado por las identidades chilotas. Por lo tanto, el proceso de industrialización incidió en los modos de vida y en las expresiones culturales que se han ido modelando dentro de las interacciones contextuales y dialógicas del archipiélago y sus habitantes. Al respecto, Claude y Oporto (2000) destacan el impacto de los cambios en los siguientes términos:

\section{tersitarias 43} 10
[...] los lugareños, al emplearse, han tenido que dejar de trabajar la tierra y abandonar la pesca artesanal, alejándose de sus costumbres y sus riquezas naturales. De esta manera, han pasado de una categoría en la cual ellos eran sus propios dueños a una categoría de dependencia frente a terceros para subsistir, vendiendo sus tierras, empobreciendo la familia, adquiriendo hábitos no deseables y contribuyendo más a la desaparición de la cultura chilota (p. 43).

Sin embargo, considerar que las prácticas culturales y los rasgos identitarios puedan dejarse de lado y reinventarse cabalmente en un nuevo escenario es ignorar el carácter enraizado que poseen estas formas representativas de la inteligibilidad humana. Si se entiende a la cultura como "los valores que comparten los miembros de un grupo dado, a las normas que acatan y a los bienes materiales que producen” (Giddens, 1991, p. 65), entonces sería más correcto hablar de una tensión de las formas culturales, más allá de un cambio rotundo de estas y de los elementos identitarios.

En este escenario conceptual, al hacer el contrapunto entre una expresión identitaria con respecto a su contexto sociohistórico, aparece un quiebre con el pasado (Román, 2015), que, como se ha mencionado, rompe con el cariz tradicional de sus habitantes, desde lo cual el principal escenario de disputa entre las formas identitarias es su contexto mismo. Esto tiene que ver con las posibilidades de uso y ejercicio del territorio. En este sentido, "es el uso del territorio y no el 
territorio en sí mismo el objeto del análisis social" (Santos, 1996a, p. 123), dado que el espacio geográfico se constituye como producto social (Rodríguez, 2010).

\section{Discursos e imaginarios: ayer y hoy en Chiloé}

A partir de los discursos de las y los entrevistados, se puede identificar que las caracterizaciones que realizan en términos identitarios están marcadas por un antes y un después, teniendo como período de inflexión la llegada de la industria salmonera (Gobantes \& Frías, 2015). Ambas instancias vinculan fuertemente el espacio geográfico como elemento constitutivo de una identidad chilota, lo cual redunda en el hecho de que, al ser intervenido el espacio geográfico por un proceso de industrialización, también se intervienen las formas identitarias y prácticas culturales.

De las entrevistas emergió un discurso identitario que se sitúa previo a la llegada de la industria salmonera, en el cual aparece muy marcada la figura de la familia, el contacto con la tierra y el mar, la solidaridad y el espacio geográfico como un 'paraíso'. Esto sugiere que, para comprender la identidad chilota de antes de la década de 1980, habría que "poner el componente de rigor, sea este el frío, sea este la lluvia, sea este el viento, sea este la relación con las personas, las formas de alimentarse, la tenencia de agua o no, la tierra" (comunicador social, comunicación personal, 30 de agosto de 2017), es decir, el entorno cultural y natural del cual son parte. Además, se vincula al hecho de considerar al archipiélago como un pedazo de espacio más o menos marginado de las dinámicas y flujos del resto del continente (Román, 2015), lo cual es valorado en términos de conservación de una identidad tradicional: "Hace 30 años éramos una isla, que podríamos decir autónoma [...]. Trabajábamos todos juntos y se veía cómo nuestra gente crecía económicamente todos por igual, sin avaricia, sin envidia, se veían muchas más familias unidas" (dirigente social, comunicación personal, 3 de septiembre de 2017).

El punto de inflexión que significó la llegada de la industria salmonera (Román, 2015) implicó, desde el discurso de los habitantes entrevistados, una ruptura con dicho pasado, así como con sus prácticas cotidianas y culturales. En este sentido, se da cuenta cómo, a través de los testimonios, se evidencia un cambio en el escenario geográfico con respecto a las dinámicas de socialización y de hacer cotidianidad en el archipiélago de Chiloé. Así, no es solo un cambio de dicho territorio, sino en el uso y potestad sobre este: "Antes se veía mucho más la solidaridad entre el chilote, bueno por eso también tenemos la minga, por ejemplo. Pero hoy día ya como que se ha perdido esa costumbre, básicamente porque la gente que estaba en el campo ha tenido que migrar a la ciudad [...] Entonces ya no se ve tanto esa solidaridad que se veía antiguamente, hoy día se trabaja en base territarias 43 
a plata" (dirigente sindical de pescadores artesanales, comunicación personal, 29 de agosto de 2017).

No obstante, este proceso de cambios tampoco aparece como algo acabado, sino más bien como un período que adopta un cariz eminentemente impuesto, pero que ha sido interiorizado poco a poco por sus habitantes, no sin diversas formas de expresión de desencuentros culturales. Por ejemplo, existe un fuerte desajuste entre las dinámicas de trabajo del campo con respecto al trabajo asalariado dentro de la industria salmonera o el sector público, proceso que luego de más de 20 años comienza a presenciar un progresivo recambio generacional dentro de la fuerza de trabajo.

En este escenario, es que las y los entrevistados dan cuenta de discursos que se posicionan críticamente respecto del proceso que ha vivido Chiloé desde la década de 1980, aunque también esgrimen un juicio crítico en cuanto a cómo los habitantes del archipiélago han afrontado dichos cambios:

Yo creo que ahí tenemos que hacernos un mea culpa todos, porque, como te decía antes, no hemos tenido la capacidad de poder posicionarnos y de tener de alguna manera esa capacidad de manifestar y poder exigir cuáles son nuestros derechos. Nosotros en el último tiempo hemos sido vulnerados de todas las formas que se pueden ver, y la gente no tiene la capacidad de exigir ni hacer valer los derechos que a nosotros nos corresponden, que somos una persona de derecho, nosotros tenemos derecho a salud digna, a vivir de forma digna (dirigente social, werken huilliche, comunicación personal, 3 de septiembre de 2017).

No es menor mencionar que la sensación de culpa y de una responsabilidad no asumida colectivamente aparece en un número importante de entrevistas y conversaciones informales sostenidas en el marco de la investigación. A partir de allí, se puede extraer que el período previo a la inserción del archipiélago en el mercado mundial constituye un escenario en donde la relación con el entorno, es decir, con el espacio y la naturaleza, constituía una forma de habitar particular que exigió una vinculación compleja y densa entre los habitantes del archipiélago de Chiloé, pero también consigo mismos y con las disposiciones ecosistémicas de este.

Sin embargo, desde la progresiva llegada de nuevas empresas y nuevas lógicas de intercambios económicos, esta relación entre habitantes y naturaleza pasa a perder aquello que la hacía distintiva: "Lo digo porque cuando tú hablas de chilote hablas de un territorio, de un maritorio y de una forma de vida particular, pero cuando esto se comienza a parecer a la forma de vida de cualquier ciudad, se globaliza" (trabajadora comunitaria, comunicación personal, 30 de agosto de 2017).

En este sentido, se puede señalar que producto de una reconfiguración en el uso del territorio se reorienta también el 
peso que este juega en las constituciones identitarias (Benach \& Albet, 2010) de Chiloé. Por un lado, se muestra que en el imaginario sobre costumbres el territorio tiene una fuerza particular en las identidades chilota, pero también los discursos dan cuenta de una especie de asesinato simbólico de dicho lugar. Por lo tanto, en primera instancia, se puede reflexionar en torno a una eventual muerte de aquellas identidades, no obstante, todo esto lejos de ser un absoluto se constituye como un proceso en constante movimiento, donde estas identidades tradicionales se ven fuertemente permeadas, afectadas y resignificadas. Desde lo anterior se puede mencionar que aquella identidad tradicional queda cristalizada (ya no en movimiento) en un recuerdo más o menos folclorizado: “[...] yo creo que está en proceso de transformación. Hay una fuerte presencia de la folclorización de sus costumbres a partir de un elemento político que busca establecer un discurso político determinado, ligado a la modernización al mercado. Por ejemplo, en la tenencia de bienes" (comunicador social, comunicación personal, 30 de agosto de 2017).

Sin embargo, que desde los discursos el imaginario se manifieste al territorio como algo muerto implica ante todo una reorganización en las dinámicas de poder que sobre este se ejercen, lo que trae aparejado nuevas formas de comunicación e intercambio en el archipiélago de Chiloé. Esto redunda en nuevas dinámicas de administración, esta vez bajo un lenguaje institucional y organizacional que no solo genera un quiebre temporal con aquella identidad pasada, sino que además significa un quiebre con el arraigo simbólico que guardan los habitantes con el territorio.

A partir de allí, este fenómeno puede entenderse, en primera instancia, como una complejización de las dinámicas de relación con el espacio geográfico (Benach \& Albet, 2010), pero que a nivel personal significa una despersonalización de ese habitante con dicho lugar. De este modo, se pierde el carácter dialógico que los habitantes tenían con aquel espacio para avanzar a una progresiva desterritorialización del archipiélago. Por lo tanto, si bien la población ha ido creciendo numéricamente, tanto la capacidad de injerencia y relación con el entorno ecosistémico como la capacidad de ejercicio de poder sobre dicho territorio se han diluido conforme los procesos de la modernidad adquieren mayor injerencia y complejidad en Chiloé.

\section{Tensión a partir de lo instituido y lo resistente}

Las identidades chilotas, en términos generales, aparecen cruzadas por un sinnúmero de influencias nuevas producto de un proceso de industrialización que tiene su expresión en términos locales. Las identidades tradicionales, mediadas por relaciones interpersonales directas, transitan hacia un tipo de organización con un fuerte componente organizacional, territarias 43

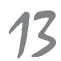


${ }^{3}$ Dicho recuerdo se ve precarizado, como sugiere Bustos (2015), por la existencia de una defensa relativa de la industria salmonera por parte de quienes viven en el territorio, en la medida en que esta es leida como una fuente de empleo y movilización de capital económico.

territarias 43 ocasionando un quiebre que se manifiesta en este nuevo abanico de diversas y variadas identidades. Es a partir de este mismo contexto que emergen discursos que operan como mecanismos que manifiestan una expresión de resistencia a dicho proceso, los cuales, sin hallarse exentos de tensiones, se construyen a partir de una resignificación del pasado tradicional como fuente de futuro. En conjunto con esa gramática, que apela a una recuperación territorial en el interior del archipiélago de Chiloé, también aparecen formas de subjetivación que se constituyen como identidades de resistencia, pero que aún no han sido capaces de proyectar una identidad colectiva a futuro, es decir, desde estas identidades de resistencia, que construyen un discurso crítico respecto de la sociedad actual, no han logrado todavía erigir un proyecto de sociedad que replantee ese pasado al cual apelan como una posibilidad de futuro; en este contexto, la incertidumbre cala hondo en los diagnósticos que hacen sobre su situación actual:

Creo que la incertidumbre pudiese ser algo estructural, algo que está acusando [...] quizá mis sentimientos, no es solo mío, me da la impresión de que es un sentimiento que está abrigando a muchas personas de acá, sino a todos, de cómo va a ser después, mira, podríamos hablar como los viejos, puede venir otro gobierno y la cuestión va a ser siempre igual, pero también puede ser que ese siempre igual sea peor, porque igual no es bueno, el igual no existe, siempre va bajando, entonces, aquí no va a llegar una industria que te salve, no va a llegar más trabajo, así como se está viendo, viene un puente, viene el sistema eléctrico central, vienen las mineras, por lo pronto está el saqueo de todas las materias primas (comunicador social, comunicación personal, 30 de agosto de 2017).

Desde las y los entrevistados, se puede evidenciar un arraigo territorial vinculado con la nostalgia del pasado, el cual se ancla como un ingrediente constitutivo de aquello que aspiran retomar. No obstante, en el tiempo presente deben disputar esos anhelos con las resignificaciones territoriales que tienen un alcance mucho más estructural; ello afecta sus mismas prácticas y disposiciones cotidianas. Dicho así, hay un cambio y tensión en el espacio vivido entre la administración efectiva del territorio y los anhelos particulares hacia este. La cotidianidad y la constitución cultural del día a día oscilan en un plano de tensión entre un gozo parcial de los servicios de las lógicas del mercado liberal y la añoranza de un pasado cuyo recuerdo ha sido precarizado. ${ }^{3}$ Sin embargo, esa situación puede plantearse considerando distintos nodos o tensiones, a saber:

1) Un análisis del panorama socioeconómico muestra una industrialización que dinamiza la economía en el archipiélago, no obstante, a la base experiencial de todo ello aparece la precariedad económica y una dependencia al sistema formal 
de trabajo asalariado. 2) Por otro lado, también implica el acceso a servicios y bienes de consumo, lo cual genera una dependencia sobre la dinámica industrial. Esta dependencia no aparece visibilizada en los discursos de las y los entrevistados, sin embargo, sí es referida la experiencia vivida a diario a partir del acceso a bienes y servicios.

La crítica al proceso de industrialización de Chiloé (Román, 2015) se manifiesta hacia un escenario macro en donde no alcanza a ser vinculado con la cotidianidad del hogar, por lo tanto, los discursos realizan un ejercicio crítico del sistema que no llegan a tocar su rol como consumidores de estos bienes y servicios. Siguiendo a Lefebvre (2013), puede plantearse una tensión en dos niveles de abstracción, un nivel vivido y otro percibido. Siendo el primero la imagen de una cotidianidad de consumo y de dependencia económica (latente); y el segundo, un diagnóstico macro respecto de la actual situación del archipiélago (manifiesto), el cual redunda en las formas de vida y las expresiones de dependencia, no obstante, no se realiza una reflexión sobre sus formas de agenciamiento en aquel escenario.

Si bien lo expresado anteriormente da cuenta de una omisión discursiva respecto de sus modos de vida, sí habría un ejercicio de cuestionamiento sobre el devenir de la sociedad chilota, tomando una responsabilidad discursiva en el proceso. Este se conforma por un discurso pesimista y de añoranza en la clave expresada por Claude y Oporto (2000), acompañado de una forma de vida en buena parte avasallada por los procesos de la modernidad, que ha arrasado con un espacio natural que a la vez fue público, y desde allí ha sido visto como usurpado y privatizado. Nuevamente en los procesos macro la tensión se expresa a partir de una desterritorialización general que conlleva una reorientación de prácticas y vivires cotidianos, sin embargo, a nivel micro o comunitario, subyace un ejercicio de resistencia a una lógica modernista que ha desnaturalizado aquello que denominan tradición.

Por lo tanto, es en estos niveles micro en donde aparecen las potencialidades de resistencia política activa, pero que no están exentos de disputa (De Sousa Santos, 2001). A partir de ahí, se da cuenta de que el puente que une estos distintos niveles de incidencia y comprensión territorial se encuentra vinculado por la esfera económica: aquí es donde, en última instancia, se juegan las trincheras reales e íntegras sobre una historia reciente marcada por el clivaje de la industrialización del archipiélago de Chiloé. Si bien el valor de esa tradición subyace en las relaciones familiares, el encuentro y la solidaridad, los aspectos condicionantes de ello se encuentran arraigados en la posibilidad económica de poder desenvolver tales asuntos. No obstante, ello se disputa en un escenario que está mediado por quien detenta el control territorial del espacio chilote. 


\section{Mayo Chilote como imagen de identidades de resistencia: entre la negación y el reconocimiento}

En este escenario es que se plantea el Mayo Chilote como un punto de inflexión discursivo y simbólico, donde, más allá de estudiar este suceso desde una entrada analítica propiamente de la acción colectiva, se plantea hacerlo como la expresión tangible de discursos disidentes respecto del proceso de resignificación identitaria a partir del territorio.

Las valoraciones que hacen las y los entrevistados respecto de lo que llaman el Mayo Chilote están compuestas de apreciaciones pesimistas respecto del impacto que lograron con aquellas movilizaciones. En primera instancia, expresan que, a pesar de la fuerza que logró el movimiento, no se pudo conseguir aquello que buscaban o los horizontes que cada uno tuvo respecto de los resultados, los cuales van desde la consecución de bonos para los pescadores hasta volver a un pasado añorado. Sin embargo, todos los discursos dan cuenta de que el Mayo Chilote constituyó una fuerza que hasta entonces se había encontrado latente, que explotó en un momento determinado y debido a situaciones específicas.

Convergen en su análisis en que, si bien había peticiones concretas, la razón de sus movilizaciones guardaba, de forma más o menos implícita, un motivo más estructural que contingente. No obstante, al momento de realizar un análisis de la efectividad del movimiento, este es visto como un fracaso y una derrota por parte del sistema hacia los habitantes: "Mayo Chilote nunca se cumplió. Te solucionaron algunos problemas con el bono, que el bono no le sirvió a nadie, o sea, sirvió en parte" (dirigente sindical de pescadores artesanales, comunicación personal, 29 de agosto de 2017).

Por lo tanto, se debe mencionar que existe una disonancia discursiva entre los indicadores de valoración del movimiento con respecto a los símbolos implícitos que acarrea y que aparecen en las distintas entrevistas. Esta disonancia valora negativamente al movimiento a partir de la movilización de recursos y consecución de las peticiones. Sin embargo, también deja de considerar los aspectos simbólicos de este; a saber, el hecho de constituirse como una mediatización y consolidación de una colectividad de identidades de resistencia respecto de las identidades impuestas en el actual contexto (De Sousa Santos, 2001). Aquí aparece una divergencia en los códigos de lectura, donde las gramáticas de valoración del Mayo Chilote tienen un fuerte componente extranjero al archipiélago, a pesar de ser paradojalmente erigidas desde un grupo de personas críticas al proceso actual de industrialización.

Si bien aquellas identidades apelan a una valorización del pasado como horizonte de proyección aún sin forma, en desmedro de una hiperconectividad, las formas de analizar las situaciones están 
Figura 1. Bonos: "Pan para hoy, hambre para mañana”

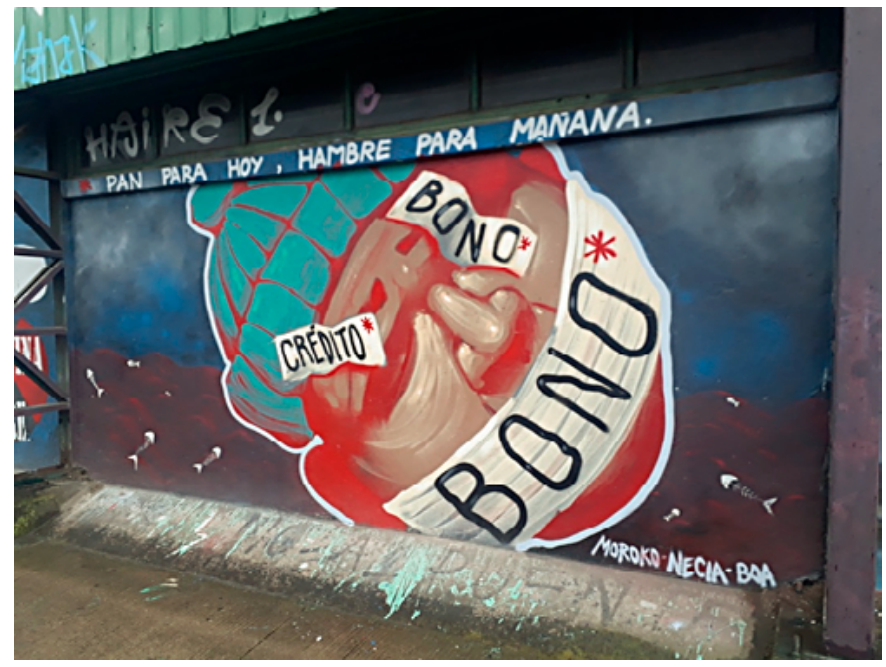

Fuente: Robledo y Peña (2017).

fuertemente permeadas por dinámicas que hasta hace 30 años eran ajenas al archipiélago y son las mismas que rechazan. No obstante, de forma muy incipiente se deja entrever una valoración simbólica del movimiento, por lo que se pueden identificar dos discursos: 1) aquel que hace una valoración sobre los resultados del movimiento a partir de las negociaciones; y 2) aquellos discursos que otorgan un valor en función de la fuerza e impacto logrado.

En el análisis efectuado, pareciera ser que la primera forma absorbe a la segunda cuando se habla de dichos acontecimientos, anulando también el potencial de proyección de dicho movimiento en términos identitarios y de sociedad a futuro (Castoriadis, 2013). Es decir, no se logra verbalizar al movimiento como una imagen de las identidades de resistencia.

Lo anterior redunda en una imposibilidad de practicar un proyecto a futuro que dispute el escenario territorial y la dinámica de poder, toda vez que las formas de acción y evaluación de estas se constituyen en buena parte desde códigos y lenguajes ajenos. En este sentido, se puede mencionar que los habitantes de Chiloé que se enmarcan dentro de un pensamiento disidente al proceso de industrialización realizan un ejercicio crítico del contexto en el que se encuentran, así como también muestran una claridad relativa respecto del pasado como proyección (Giddens, 1991). Sin embargo, si bien generan aquel diagnóstico, aún no logran constituir un discurso colectivo que proyecte esas territarias 43 
${ }^{4}$ No es el foco del presente articulo discutir las relaciones sindicales establecidas en el archipiélago. Para una revisión más extensa del sindicalismo en dicha zona, refiérase a Ganga y Allendez (2007), Rebolledo (2012) y Mühle, Rodriguez y Torres (2011).

territarios 43

Figura 2. "Pensemos el mundo desde Chiloé, no Chiloé desde el mundo"

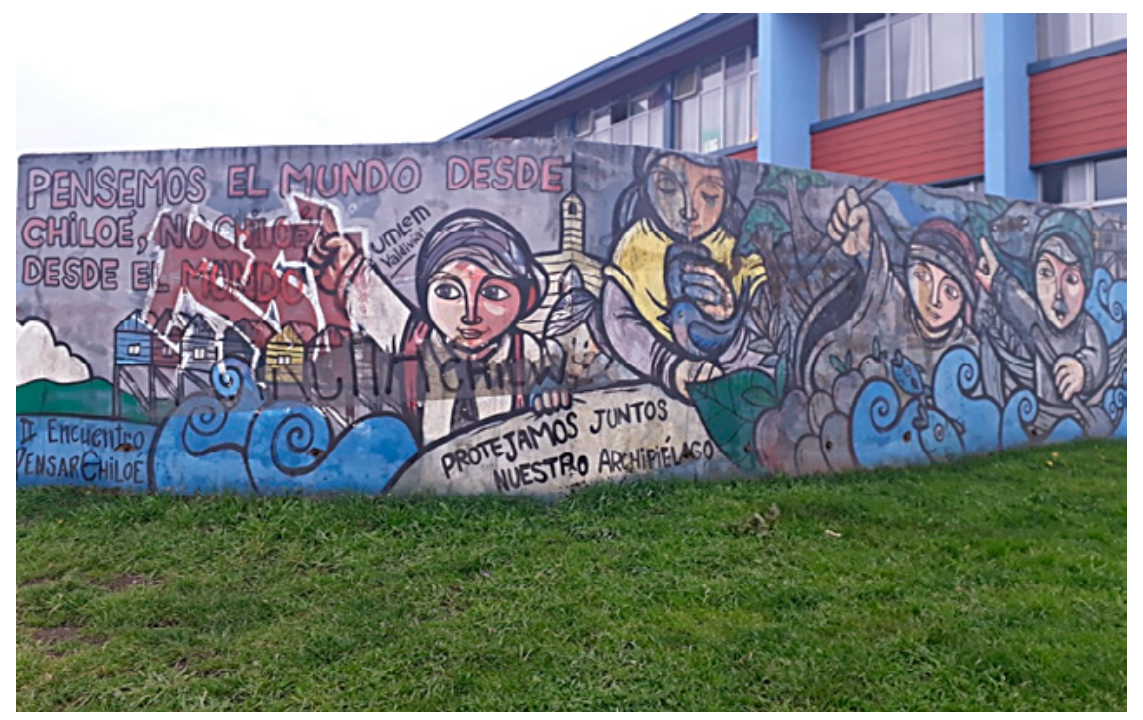

Fuente: Robledo y Peña (2017).

intenciones y que además dé cuenta de ello en el tiempo presente.

Por ende, a la base de esta situación tal parece que radica una falta de reconocimiento discursivo entre las diversas individualidades que convergen en una unidad de proyección. Esta falta de reconocimiento no implica el hecho de que no se conozcan como personas naturales, sino que se manifiesta en un desconocimiento respecto del potencial de constitución subjetiva que poseen sus discursos y proyecciones aún difusas. Este imaginario que se forma revalorizando lo propio y lo pasado no logra articular mecanismos de disputa territorial frente al proceso de movimiento de capital transnacional. Si bien existen formas de articulación colectiva, como los sindicatos, estos aparecen discursivamente deslegitimados y cooptados por otros actores, lo cual implícitamente da cuenta de que son formas de colectivización aún ajenas al proyecto de estas identidades de resistencia. ${ }^{4}$ En este sentido, el valor que adquiere el Mayo Chilote (pero que aún no ha sido sólidamente verbalizado por sus protagonistas), más allá de la derrota material que supuso, es que puede ser leído como la representación performática de una gramática discursiva - en el sentido de Cegarra (2012) - crítica al proceso que actualmente se desenvuelve en el archipiélago de Chiloé, lo que implica una visibilización contingente de identidades críticas que aún buscan articularse. 
Figuras 3 y 4 . Convocatorias a instancias de reflexión sobre el Mayo Chilote
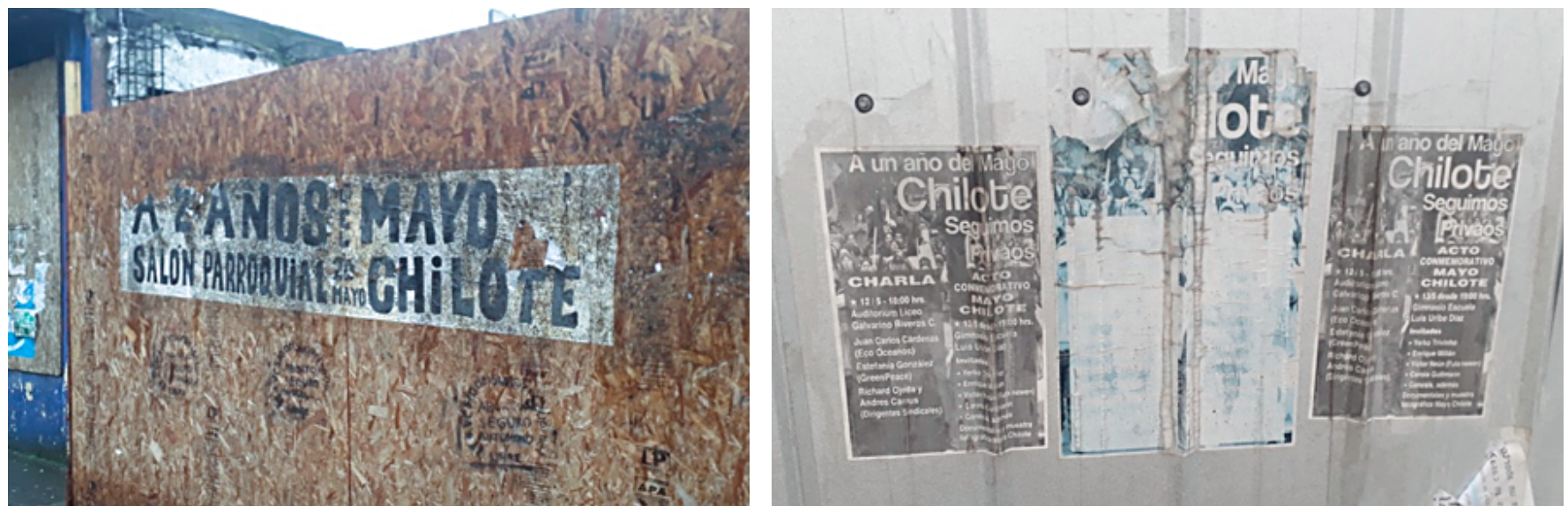

Fuente: Robledo y Peña (2018).

Esto permite posicionar en el escenario social sus discursos y habilitar una inercia de socialización e interiorización de estas formas de constitución identitaria: “[...] empezaron a construir un, cómo decirlo, un imaginario de defensa de esta situación, de lo propio, de lo que hay acá, versus la industria salmonera, el hecho de que la industria salmonera esté estigmatizada como mala, como algo malo significa que entonces hiciste algo bueno" (comunicador social, comunicación personal, $30 \mathrm{de}$ agosto de 2017).

Las identidades de resistencia del Mayo Chilote tienen como particularidad erigirse desde una experiencia que, producto de trayectorias biográficas específicas, ha sido testigo y parte de los cambios que se han vivido en el archipiélago. Los discursos manifiestan una profunda sensación de incertidumbre estructural, como también un progresivo desarraigo territorial y de memoria, que acaece en Chiloé. Con este antecedente se puede manifestar que los cambios estructurales generan una identidad impuesta que se constituye a partir de un desarraigo espacio-temporal proyectivo, como también un desarraigo espacio-temporal retrospectivo. En otras palabras, son identidades caracterizadas por un desarraigo territorial y temporal, ya que ni el pasado ni el futuro se asocian a una constitución identitaria fuerte, originando un presente dotado de incertidumbre y una espacialidad flotante.

No obstante, la particularidad de los discursos identitarios de resistencia denota relación con una gramática que tensiona, al menos discursivamente (Cegarra, 2012), dicho proceso de inserción en el concierto global. En este contexto, y dados ciertos aspectos contingentes, así territarias 43 
como la agudización de tensiones asociadas a una economía extractivista, es que esta gramática discursiva se traduce en la irrupción de lo que fue el Mayo Chilote. Entendiéndose este proceso como una imagen producida por imaginarios de identidad de resistencia, en un contexto particular, pero que a su vez constituye una habilitación experiencial generadora de nuevos sentidos de pertenencia y de relación histórico-espacial (Berroeta, Ramoneda, Rodriguez, Di Masso \& Vidal, 2015), toda vez que dicho proceso estuvo marcado, en términos cotidianos, por un restablecimiento y acercamiento de prácticas y valores 'tradicionales' (Giddens, 1991), restituyendo algunos códigos valóricos respecto de la identidad y el territorio. Sin embargo, aquello aún debe ser verbalizado y, más aún, consolidada esa imagen por sus protagonistas.

\section{Conclusiones}

El territorio chilote se revela en las entrevistas como escenario de disputa. Por un lado, se cuestionan las dinámicas y flujos productivos, mas no así la matriz extractivista. Por el otro, se asiste a una disonancia identitaria al generar numerosos modos de estar siendo en el territorio, desde lo cual implica diferencias radicales en cuanto a los modos de constituir subjetivamente el territorio habitado, así como las subjetividades identitarias de los mismos chilotes.

En este sentido, el espectro por las formas de uso del territorio da cuenta de variadas y complejas nomenclaturas de proyección de futuro permeadas tanto por la certidumbre de la destrucción de la naturaleza como por la incertidumbre respecto de un futuro que en el presente actual (asumiendo una diversidad integral de $f u$ turos-presentes) implica una disonancia que se desarraiga temporalmente del pasado y de una proyección incierta del futuro, así como también una desintegración del lazo social que comporta la materialidad del territorio como ingrediente fundamental de la constitución identitaria del chilote. En este sentido, cabe mencionar que la reorientación identitaria, al igual que las prácticas culturales cotidianas, sufren un cambio que se asocia, por un lado, a una desterritorialización de los habitantes; $y$, por otro, a escenarios de acción que escapan a la capacidad de significación de estos.

Específicamente, la identidad chilota aparece significada como una identidad fragmentada con su pasado reciente, producto de la incidencia de profundos cambios que han reorientado disposiciones estructurales hacia las formas de vida $y$ socialización tanto en el interior del archipiélago como con los flujos vinculados hacia afuera (a escala nacional e internacional). Por lo tanto, esta fragmentación sería también una reconfiguración de la identidad misma. Así mismo, la valoración de aquello en que se ha convertido el territorio chilote sigue una línea sobremanera similar con las percepciones de identidad. Sin perjuicio de ello, los discursos de las 
y los sujetos entrevistados se posicionan desde una autorreferencia identitaria de resistencia con respecto al actual escenario chilote, poniendo como horizonte un futuro enraizado en el pasado, visto ajeno en términos de las posibilidades fácticas de ser llevado a cabo producto de condicionantes estructurales. Es decir: no hay un discurso que dé cuenta de un proyecto futuro.

Si bien pareciera haber un consenso en que la identidad chilota se arraiga en la naturaleza, las identificaciones sobre el ser chilote se encuadran dentro de dinámicas arraigadas en un pasado que ha sido relegado a mera expresión folclórica del recuerdo de una tradición. En última instancia, la definición tradicional del chilote parece ser una fotografía imaginaria del pasado, no obstante, de forma muy latente la imagen contemporánea del chilote aparece en los discursos asociados a las actuales formas de vida moderna, donde efectivamente se da cuenta de un quiebre con el pasado que se expresa fuertemente en los códigos de socialización legitimados y masificados dentro del archipiélago.

Por lo tanto, se deja entrever cómo estas formas cotidianas de socialización han redundado en una identidad que se ha hecho cada vez más permeable a incidencias externas y productos culturales enmarcados dentro del proceso de globalización y de flujos transnacionales de capital y mercancías. Lejos de mencionar que no existe un ejercicio reflexivo respecto de cómo esta identidad ha ido mutando, habría que explicitar que no ha sido propiamente expresada por los entrevistados en sus discursos; sin embargo, dejan huellas de una progresiva verbalización de aquella autoimagen identitaria.

Estas huellas se expresan principalmente en una visión crítica del proceso que ha vivido el archipiélago desde la progresiva instalación de la industria salmonera (Román, 2015) y, consecuentemente, con la llegada masiva de tecnologías y formas de socialización contemporáneas ya mencionadas. Por ende, una de las formas de expresión que constituye una identidad de resistencia serían las movilizaciones del Mayo Chilote, toda vez que es una expresión discursiva que trajo consigo una gramática de socialización asociada a un pasado añorado y vulnerado en el contexto actual. Desde ahí, los actores entrevistados rescatan al Mayo Chilote como una expresión de descontento gatillado por una situación insostenible que se relaciona desde sus perspectivas con una vulneración del territorio marítimo (o maritorio) y que, por lo tanto, habría sido una expresión de violencia contra formas identitarias tradicionales arraigadas espacialmente.

En este sentido, cabe destacar que la sensación de desencanto con el proceso de movilización cala hondo en los discursos y valoraciones del mismo proceso. Por un lado, este es significado como la puesta en escena de una figura escénica alusiva a un pasado positivamente valorado que de cierta forma implicó una apertura a lo territarios 43 
tradicional, utilizándolo como referente constitutivo de una identidad de resistencia. Pero se debe mencionar que aquella significación del movimiento, en tanto puesta en escena, como proceso dotado de significantes tradicionales, se constituyó como una movilización que no pudo cristalizarse en anhelos y expresiones más profundas respecto de sus perspectivas de sociedad futura.

Por lo tanto, la irrupción de los procesos de industrialización insertos en el contexto chilote constituye un desanclaje con el pasado, pero también implica una afección al territorio mismo donde ese pasado se encontraba incrustado. En consecuencia, el Mayo Chilote se supone como una reterritorialización del pasado que, no obstante, no es visibilizada íntegramente por sus actores, y que, por lo tanto, acarrea una latente posibilidad de reinterpretación proyectiva de aquella identidad y un marco de reconocimiento de dichas identidades de resistencia aún no explorado por sus protagonistas.

En los discursos de los entrevistados, se da cuenta de una suerte de negación del proceso de movilización, pues es visto y juzgado en función de un sentido pragmático más que como una imagen que contribuye a edificar una gramática de resistencia identitaria. Así pues, el Mayo Chilote es visto como una derrota política y social que va desde el Estado y las distintas industrias hacia los chilotes. Esto se debe a que las formas de analizar territarias 43 y conducir el proceso de movilización se realizaron en clave de consecución de recursos a partir de negociaciones; sin embargo, al hilar más profundo en las implicancias ontológicas de las identidades de resistencia, se da cuenta de que el Mayo Chilote aparece como una expresión tangible de dichas gramáticas discursivas.

En consecuencia, hay una valoración del proceso que aún es parcial, pues la movilización es asociada a una negociación que no se condice con las retribuciones conseguidas en el marco temporal de aquel proceso. Así mismo, se debe destacar que el nodo que gatilla el proceso de movilización y sus siguientes acciones es enmarcado dentro de problemáticas contingentes, habida cuenta de que fue ocasionado por disposiciones estructurales. Desde las entrevistas realizadas, las interpretaciones consecuentes que se hacen del mismo proceso están asociadas a una derrota política, pero también a una disolución de las relaciones sociales que se tejieron en ese marco del movimiento, las cuales se encontraban inspiradas en aquello que llaman 'identidad chilota tradicional'. En este marco, se puede expresar que la desembocadura del Mayo Chilote devino no solo en un proceso de negociación, sino en una anulación parcial de la imagen identitariamente resistente, puesto que los actuales discursos respecto del Mayo Chilote expresan una desilusión y decepción de aquella imagen.

Finalmente, la gramática discursiva actual no permite una significación más profunda de aquel proceso como 
un enclave habilitador de formas interpretativas de identidad. A partir de allí, se puede entender el proceso del Mayo Chilote como una reterritorialización del pasado latente, pero que, en términos discursivos, no ha sido significada en torno a la gramática que la habilita a constituirse como una imagen de resignificación y constitución identitaria: no se ha otorgado el valor como imagen que ayuda a erigir y solidificar identidades de resistencia. Esta es una tarea que queda pendiente para aquellas subjetividades que pretenden oponerse a los cambios estructurales que hoy en día acaecen en el archipiélago de Chiloé.

\section{Referencias}

(2016). Chao pescao: el fin del sueño salmonero en Chiloé. El Mostrador. Recuperado de http://www.elmostrador.cl/noticias/pais/2016/05/11/ chao-pescao-el-fin-del-sueno-salmonero-en-chiloe/

(2018). Vertido de salmones en Chiloé en 2016 fue ilegal. Radio Universidad de Chile. Recuperado de https://radio. uchile.cl/2018/05/23/vertido-de-salmones-en-chiloe-en-2016-fue-ilegal/ Agudelo, A. (2011). (Des)hilvanar el sentido/los juegos de Penélope. Una revisión del concepto de imaginario y sus implicaciones sociales. Uni-pluri/ versidad, 11(3), 1-18.

Álvarez, R., \& Hidalgo, C. (2018). La movilidad insular "asfixiada” en el mar interior de Chiloé. Recuperado de https://www.researchgate.net/ profile/Carlos_Hidalgol1/publication/330600862_La_movilidad_insular_asfixiada_en_el_Mar_Interior_de_Chiloe/ links/5c4alb5b299bf12be3e079cc/ La-movilidad-insular-asfixiada-en-elMar-Interior-de-Chiloe.pdf

Benach, N., \& Albet, A. (2010). Edward W. Soja: la perspectiva postmoderna de un geógrafo radical. Barcelona: Icaria.

Beriain, J. (1996). Las consecuencias perversas de la modernidad. Barcelona: Anthropos. Doi: http://dx.doi. org/10.5565/rev/papers/v54n0.1921

Berman, M. (1978). Todo lo sólido se desvanece en el aire. Madrid: Siglo XXI Editores.

Berroeta, H., Ramoneda, Á., Rodriguez, V., Di Masso, A., \& Vidal, T. (2015). Apego de lugar, identidad de lugar, sentido de comunidad y participación cívica en personas desplazadas de la ciudad de Chaitén. Magallania (Chile), 43(3), 51-63.

Bogdan, S., \& Taylor, R. (2009). Introducción a los métodos cualitativos de investigación. Barcelona: Paidós.

Bourgois, P. (2009). Apertura. Treinta años de retrospectiva etnográfica sobre la violencia en las Américas. En J. López García, S. Bastos \& M. Camus, Guatemala. Violencias desbordadas (pp. 28-62). Córdoba, Argentina: Universidad de Córdoba.

Buschmann, A., Farías, L., Tapia, F., Varela, D., \& Vásquez, M. (2016). territarias 43 


\section{tersitarias 43}

Informe final: Comisión Marea Roja. Recuperado de directemar.cl/ directemar/site/artic/20180619/ asocfile/20180619134106/informe_salmones_y_marea_roja.pdf

Bustos, B. (2015). ¿ ¿Síndrome de Estocolmo? Comunidad, industria y desarrollo tras la crisis del virus ISA en Chiloé. En Á. Román, J. Barton, B. Bustos \& A. Salazar (Comps.), Revolución salmonera. Paradojas y transformaciones territoriales en Chiloé (pp. 235-257). Santiago, Chile: RiL Editores.

Cancino, L. (2011). Aportes de la noción de imaginario social para el estudio de los movimientos sociales. Polis (Santiago), 10(28), 69-83. Doi: https://dx.doi.org/10.4067/S071865682011000100005

Castells, M. (1999). La era de la información: economia, sociedad y cultura. Volumen II. El poder de la identidad. México: Siglo XXI Editores.

Castoriadis, C. (1997). El imaginario social instituyente. Zona Erógena, 35, 1-9.

Castoriadis, C. (2013). La institución imaginaria de la sociedad. México D.F.: Tusquets.

Cegarra, J. (2011). La sociología fenomenológica como fuente epistemológica de los imaginarios. Última Década, 26(1), 65-90.

Cegarra, J. (2012). Fundamentos teóricos epistemológicos de los imaginarios sociales. Cinta de Moebio, 43, 1-13. Doi: https://dx.doi.org/10.4067/ S0717-554X2012000100001
Centro de Educación y Cultura Americana (CECA). (2017). A un año del "Mayo Chilote”: preguntas que siguen abiertas. Recuperado de http://cecamericana. cl/2017/03/13/a-un-ano-del-mayochilote-preguntas-que-siguen-abiertas/

Claude, M., \& Oporto, J. (2000). La ineficiencia de la salmonicultura en Chile: aspectos sociales, económicos y ambientales. Recuperado de http://www.terram. cl/wp-content/uploads/2014/08/ rppl_julio2000.pdf

De Sousa Santos, B. (2001). Los nuevos movimientos sociales. Revista del Observatorio Social de América Latina/ OSAL, 5, 177-188.

De Sousa Santos, B. (2013). Descolonizar el saber, reinventar el poder. Santiago, Chile: LOM Ediciones.

Foucault, M. (2003). Vigilar y castigar. Nacimiento de la prisión. Buenos Aires: Siglo XXI Editores.

Ganga Contreras, F. A., \& Allendez, E. (2007). Análisis teórico del sindicalismo en la región de los Lagos - Chile, desde una perspectiva del género: situación de la industria salmonera. Universum (Talca), 22(2), 125-150. Doi: https://dx.doi.org/10.4067/ S0718-23762007000200009

Giddens, A. (1991). Sociología. Madrid: Alianza Editorial.

Giddens, A. (1995). Modernidad e identidad del yo. El yo y la sociedad en la época. Barcelona: Ediciones Península. 
Gobantes, C., \& Frías, D. (2015). Estrategias de asentamiento e integración territorial de la industria salmonera. En Á. Román, J. Barton, B. Bustos \& A. Salazar (Comps.), Revolución salmonera. Paradojas y transformaciones territoriales en Chiloé (pp. 151-180). Santiago, Chile: RiL Editores.

Hernández Sampieri, R. (2014). Metodología de la investigación. México D.F.: McGraw-Hill.

Lefebvre, H. (2013). La producción del espacio. Madrid: Capital Swing.

Mansilla Torres, S. (2006). Chiloé y los dilemas de su identidad cultural ante el modelo neoliberal chileno: la visión de los artistas e intelectuales. Alpha (Osorno), (23), 9-36. Doi: https://dx.doi.org/10.4067/S071822012006000200002

Marcuse, H. (1971). El hombre unidimensional. Barcelona: Seix Barral.

Mella, O. (2003). Metodología cualitativa en ciencias sociales y educación: orientaciones teórico-metodológicas y técnicas de investigación. Santiago, Chile: Primus.

Molina C., W. (2011). Identidad regional en Magallanes, sus expresiones simbólicas y territoriales. Magallania (Punta Arenas), 39(1), 59-69. Doi: https://dx.doi.org/10.4067/S071822442011000100003

Mühle, A., Rodríguez, M., \& Torres, V. (2011). Neoliberalismo y territorios locales: los conflictos politicos de la industria salmonera. Estudio comparativo de casos en territorios rurales de Chiloé.
Recuperado de https://estudiosmaritimossociales.org/wp-content/ uploads $/ 2014 / 01 /$ rems-nc2ba- 4 -artc3adculos-2a-1.pdf

Orduna, M. (2012). Identidade identidades: potencialidades para la cohesión social $y$ territorial. Barcelona: URB-AL III, Oficina de Coordinación y Orientación (OCO).

Pérez, S. (2017). Situando los imaginarios sociales: aproximación y propuestas. Imagonautas, (9), 1-22.

Rebolledo, L. (2012). Resistencia y cambios identitarios en trabajadores/ as del salmón en Quellón. Polis (Santiago), 11(31), 223-239. Doi: https://dx.doi.org/10.4067/S071865682012000100013

Rodríguez, D. (2010). Territorio y territorialidad. Nueva categoría de análisis y desarrollo didáctico de la geografía. Uni-pluri/versidad, 10(3), 1-11.

Román, Á. (2015). Prioridades de desarrollo en Chiloé: tres décadas de asimilación de la industria salmonera. En Á. Román, J. Barton, B. Bustos \& A. Salazar (Comps.), Revolución salmonera. Paradojas y transformaciones territoriales en Chiloé(pp. 209-234). Santiago, Chile: RiL editores.

Ruiz, J. (2016). Análisis sociológico del discurso: métodos y lógicas. Recuperado de http://www.qualitative-research.net/index.php/fqs/ article/view/1298/2776 
Sandín, M. (2003). Investigación cualitativa en educación: fundamentos y tradiciones. Madrid: McGraw-Hill.

Santos, M. (1996a). El retorno del territorio. En M. Santos (Comp.), De la totalidad al lugar (pp. 123-130). Barcelona: Oikos-Tau.

Santos, M. (1996b). Metamorfosis del espacio habitado. Barcelona: Oikos-Tau.

Santos, M. (2007). O dinheiro e o território. En M. Santos (Comp.), Território, territórios: ensaios sobre o ordenamento territorial (pp. 7-13). Río de Janeiro: Lamparina.
Seguel, M. (2008). Manejo de cultivos bivalvos contaminados con marea roja. Recuperado de vliz.be/en/ imis? refid $=133509$

Ugas, G. (2007). La educada ignorancia: un modo de ser del pensamiento. Caracas: TaPeCS.

Valdebenito Allendes, J. (2018). Twitteo, ¿luego resisto? Movilización popular y redes sociales en Chile: la marea roja de Chiloé (2016). Izquierdas, (40), 185-201. Doi: https://dx.doi.org/10.4067/S071850492018000300185 